\title{
Review
}

\section{e Timing of Platelet Rich Plasma Injections During Antithrombotic Therapy}

\author{
Ryan Ravi Ramsook, MD, and Houman Danesh, MD
}

From: Department of Rehabilitation Medicine and Department of Anesthesiology at Icahn School of Medicine at Mount Sinai

Address Correspondence: Ryan Ravi Ramsook, MD Icahn School of Medicine at Mount Sinai, 5 East 98th St., 6th Floor, Box $1240 B$, New York, NY 10029 E-mail: ramsook@gmail.com

Disclaimer: There was no external funding in the preparation of this manuscript. Conflict of interest: Each author certifies that he or she, or a member of his or her immediate family, has no commercial association (i.e., consultancies, stock ownership, equity interest, patent/ licensing arrangements, etc.) that might pose a conflict of interest in connection with the submitted manuscript.

Manuscript received: 12-02-2015 Revised manuscript received: 03-21-2016

Accepted for publication: 04-28-2016

Free full manuscript: www.painphysicianjournal.com
The use of platelet rich plasma (PRP) spans across many fields owing to its role in healing and as a natural alternative to surgery. PRP continues to grow however much of the literature is anecdotal or case report based and there is a lack of controlled trials to evaluate standards for PRP. The International Cellular Medical Society (ICMS) has developed guidelines to help with the safe advancement of PRP; however there remains a gap in literature concerning the timing of PRP injections in patients who are on antithrombotic therapy. The importance of an intact platelet surface membrane allows for the appropriate release of the healing bioproteins and growth factors granting PRP therapy its efficacy. This along with the proliferation of differentiated cells, enhancement of collagen synthesis, early angiogenesis and revascularization help promote the benefits of regeneration. The intrinsic and extrinsic pathways of the coagulation cascade are valuable in that disruption of this mechanism or prematurely activated platelets may result in limited efficacy. Anticoagulants and antiplatelet drugs are commonly used in patients who are candidates for PRP. As antithrombotic agents affect platelet stability, they will have an effect on PRP efficacy and must be discontinued at an appropriate time frame prior to injection therapy. Understanding the pharmacokinetics and platelet effects can help guide discussion on the proper timing of discontinuation and resumption of a particular antithrombotic agent. With future research, the establishment of clinical practice guidelines concerning PRP and antithrombotic therapy can help structure safe and efficacious means in which to promote healing and regeneration in a growing patient population.

Key words: Platelet rich plasma, antithrombotic therapy, coagulation, platelet activation, regenerative medicine, growth factors

Pain Physician 2016; 19:E1055-E1061
P latelet rich plasma (PRP) has been well documented in many fields after it was first used by Ferrari et al in 1987 to avoid blood transfusions after an open heart operation (1). Initial popularity touted PRP as a safe and natural alternative to surgery. By having a powerful effect of modulating cytokines, growth factors, and bioactive proteins, PRP procedures have continued to expand with the goal of healing and regeneration (2). The elective procedure is generally considered for subacute and chronic conditions; most healing slows by $6-12$ weeks after an injury (3). Some of the more common uses for PRP include tendinopathies, ligament sprains, muscle strains, joint osteoarthritis, failed conservative treatment of entrapment neuropathies, and non-union fractures
(4-6). Many patients who are candidates for PRP therapy will also be on concomitant antithrombotic therapy (7). The pharmacokinetics of each particular agent needs to be examined with longer acting anticoagulants requiring greater intervals between dosing and procedures. Further studies and testing are clearly needed to further elucidate the timing of PRP injections during antithrombotic therapy.

\section{PRP}

PRP therapy systems have several ways in which they are prepared and performed. One of the most commonly used techniques is the double spin method. In this method there is the use of blood plasma from the patient's whole blood that has been processed to 
contain a high concentration of platelets and associated growth factors. The patient's whole blood is first spun down using a centrifuge in order to allow removal of the red blood cells. At that point a second centrifuging is performed which allows the removal of the platelet rich layer. The use of an anticoagulant, while not taken systemically, is needed in the processing of PRP in order to prevent spontaneous activation. Numerous agents have been utilized including heparin, citrate, acid citrate dextrose (ACD), and citrate-theophyllineadenosine-dipyridamole (CTAD). Heparin is not typically used as it activates platelets in-vivo. Sodium citrate has also been used, but recent research has shown that it may decrease the number of dense granules and promote earlier lysis and more spontaneous activation. ACD is utilized and the platelets have more dense granules and lower spontaneous activation. CTAD has 3 combined platelet antagonists and has been used in hematologic studies. There has been a push for its use in PRP production because of decreased spontaneous activation and an increase in the amount of growth factor released (8). In terms of purposefully activating the PRP, many practitioners will use either thrombin or calcium chloride which causes the release of growth factors, signaling molecules, cytokines, integrins, coagulation proteins, and adhesion molecules $(9,10)$. Growth factors have been shown to be extremely important in wound healing and in the wound regeneration process (11). Some of the essential growth factors include transforming growth factor beta (TGF- $\beta$ ), platelet-derived growth factor (PDGF), insulin-life growth factor (IGF), vascular endothelial growth factor (VEGF), epidermal growth factor (EGF), and fibroblast growth factor-2 (FGF-2) (12) (Table 1). These factors have been shown to increase or enhance bone and soft tissue healing through a variety of ways including proliferation of osteoblast and epidermal cell differentiation, stimulating collagen synthesis, and enhancing early angiogenesis and revascularization $(13,14)$. It is important to note that data on

Table 1. Growth Factors in PRP.
Transforming growth factor beta (TGF- $\beta$ )
Platelet-derived growth factor (PDGF)
Insulin-like growth factor (IGF)
Vascular endothelial growth factor (VEGF)
Epidermal growth factor (EGF)
Fibroblast growth factor-2 (FGF-2)

Table 1. Growth Factors in PRP.

Transforming growth factor beta (TGF- $\beta$ )

Platelet-derived growth factor (PDGF) Insulin-like growth factor (IGF) Vascular endothelial growth factor (VEGF) Fibroblast growth factor-2 (FGF-2) antithrombotic agents acting on these growth factors are severely lacking, and more research is needed to better determine more specific interactions between particular agents and growth factors.

In normal healing of the musculoskeletal system, the repair response begins with the formation of a blood clot and with degranulation of platelets (15). This degranulation then causes the release of the growth factors and cytokines which trigger the expansion of local progenitor cells as well as the chemotaxis of inflammatory cells. It is thought that about $100 \%$ of the growth factors are released within the first hours, of which $70 \%$ are secreted in the first 10 minutes of activation (16). It is posited that through the use of PRP, the body's physiologic healing process can be enhanced after a musculoskeletal injury. Augmentation of this healing process by PRP has been demonstrated by increased proliferation of stem cells and fibroblasts (17). In order for these intact platelets to mediate their effects they must undergo degranulation. Naturally occurring platelet activation occurs when there is a break in the endothelium. Collagen, thromboxane A2, ADP, and thrombin are all factors that can trigger the activation, with thrombin being the most potent activator. Activation of PRP is typically done via calcium chloride or thrombin allowing for soft adhesion (18). As the majority of the platelet substances are contained in alpha granules (in addition to dense granules and lysosomes), when activated there is exocytosis of the granules and their subsequent release into the extracellular environment $(19,20)$. It is important to ensure that the platelets are intact after centrifugation or the growth factors could be diluted and lost in the plasma. As the growth factor receptors remain on the platelet surface membrane, platelet activation P selectin can be measured to ensure integrity (21).

\section{Coagulation Pathway}

After an endothelial injury to a vessel, the coagulation pathway starts almost instantly in normal individuals. Primary hemostasis occurs with platelets forming a plug at the injury site while secondary hemostasis occurs via a complex cascade with the goal of fibrin strand formation helping to strengthen the platelet plug. As previously mentioned, PRP efficacy stems from the integrity of the platelet membrane and inactivation until the timing of the PRP (22). If the coagulation pathway is disrupted and the platelets are activated prematurely, PRP may not work as predicted. It is for this reason that an in depth knowledge of the coagulation pathway in needed. 
The intrinsic pathway, or contact activation pathway, of the coagulation cascade begins with the formation of collagen's primary complex by high molecular weight kininogen, prekallikrein, and Factor XII (Hageman factor) (Fig. 1). Prekallikrein is converted to kallikrein while Factor XII is changed to Factor XIla. Then XIla converts Factor XI into Xla. Xla then activates Factor IX which along with cofactor VIla creates the tenase complex allowing for the conversion of Factor $\mathrm{X}$ to $\mathrm{Xa}$ (23). This complex activation system however is not the primary pathway for coagulation initiation.

The extrinsic pathway, or tissue factor pathway, has been shown to be the more important pathway serving the end goal of rapidly releasing thrombin. After injury to the vessel wall, factor VII comes into contact with tissue factor creating an activated complex (TFFVIIa) which in turns activates Factors IX and X. Factor VII is also activated by thrombin and Factors XIa, XII, and $\mathrm{Xa}$. The prothrombinase complex formed by Factor $\mathrm{Xa}$ and co-factor $\mathrm{Va}$, activates prothrombin to thrombin.
Thrombin then sets off the activation of other portions of the cascade including $V$ and VIII, which results in the downstream release of VIII from being bound to the van Willebrand factor. The prothrombotic state is maintained by the tenase complex until down-regulated by the anticoagulant pathways (24).

Regulators of the coagulation cascade and platelet activation include Protein $\mathrm{C}$, antithrombin, tissue factor pathway inhibitor, plasmin, and prostacyclin. Deficiencies of these regulators can lead to an increased thrombotic state. These pathways, and particularly the formation of the platelet plug, are important to consider in PRP, as platelets are the key in the proposed healing process (25). Therefore the risk of possible derailment of PRP therapy may be seen in patients with pharmacological agents aimed at disrupting platelet function.

\section{Antithrombotic Therapy}

Anticoagulants and antiplatelet drugs are commonly used in patients who are candidates for PRP. The

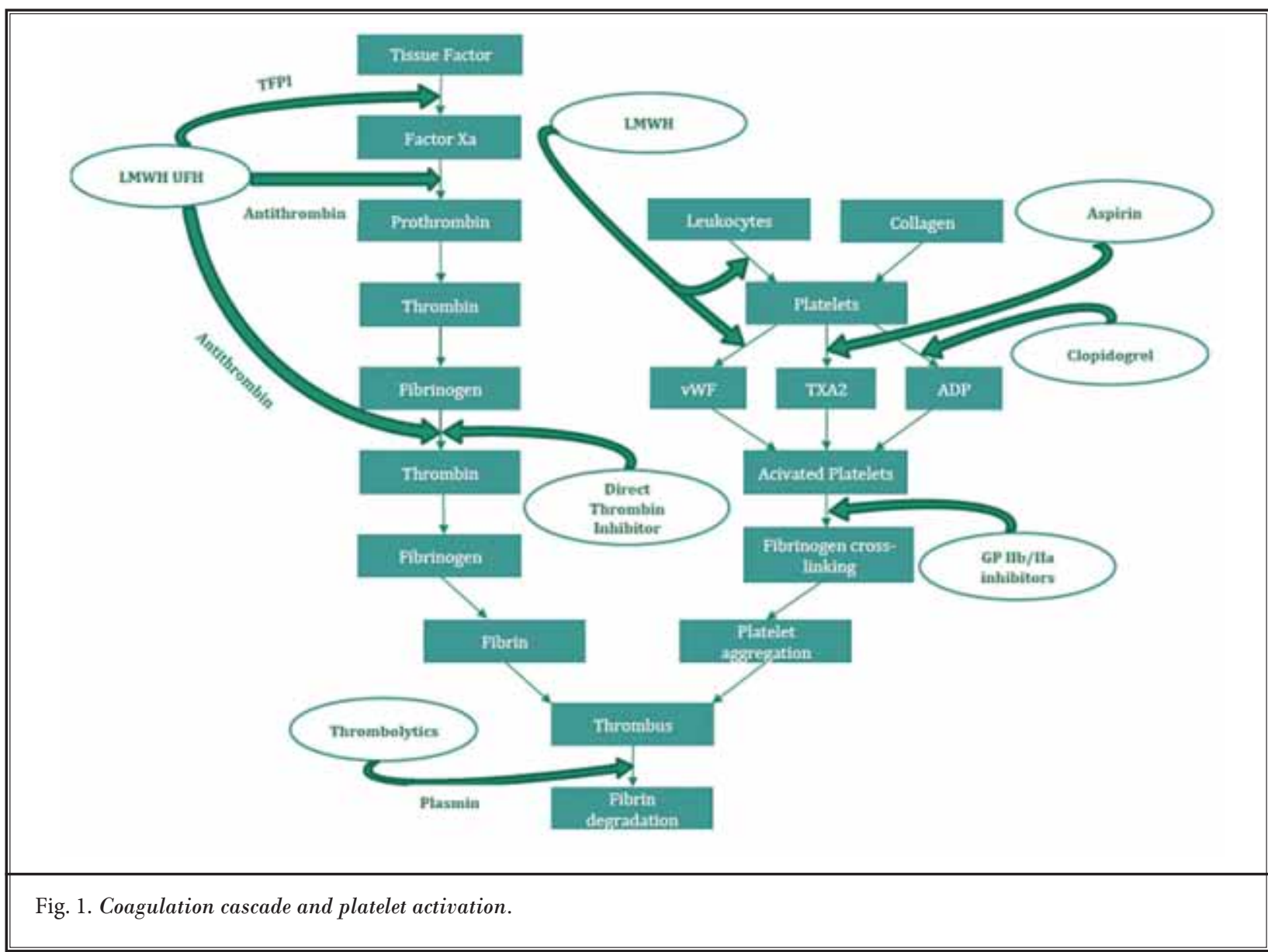


literature guiding the timing of PRP injections during antithrombotic therapy is severely lacking. Due to the importance of the platelet and their granular content effects in PRP, it is clear that agents interfering with the platelet plug, particularly factor 8 , von Willebrand factor, fibrinogen, and thrombin, can affect the efficacy of treatment. For this reason we aim to focus practitioner and patient emphasis on the safety, efficacy, and education of PRP injections in relation to commonly used antithrombotic agents. Taking into account the halflife of a drug is important as it takes about 5 half-lives in order for a drug to be cleared from the system.

Warfarin, with a half-life of $20-60$ hours should be held $4-5$ days prior to PRP injection. In order to maintain the efficacy of the PRP injection, resumption of therapy may be initiated 2 hours after the procedure (26).

Heparin, with a half-life around 1.5 hours may be held $2-4$ hours prior to injection and may be restarted one hour after. There should be no contraindications up to 5000 units twice daily (27).

Low molecular weight heparin therapeutic dosing should be held for longer than 24 hours while prophylactic dosing should be held for $10-12$ hours prior to the procedure. Therapeutic dosing can be resumed after 24 hours post procedure and prophylactic dosing $6-8$ hours after (28).

Fondaparinux is a synthetic factor Xa inhibitor with a half-life of $17-21$ hours. The agent should be held between $36-42$ hours prior to PRP injection and may be resumed $6-8$ hours post procedure (29).

Rivaroxaban was the first direct factor Xa inhibitor and has a half-life of $5-9$ hours. It should be held 22 -26 hours prior to injection and may be restarted $4-6$ hours post procedure (30).

Apixaban, also a direct factor Xa inhibitor, has a half-life of $9-14$ hours and should be held $26-30$ hours prior to injection. It may be restarted $4-6$ hours post procedure (31).

Dabigatran is a direct thrombin inhibitor, with a half-life of $12-17$ hours, should be held for 7 days and may be restarted 5 days post PRP therapy. Other direct thrombin inhibitors such as argatroban and bivalirudin are administered intravenously and are short-acting, so they may be discontinued relatively close to the initiation of the procedure (32).

P2Y12 receptor blockers are contraindicated only if there is concomitant dual antiplatelet therapy.

Clopidogrel, with a half-life of $7-8$ hours, should be held for 7 days prior to injection.
Ticlodipine, with a half-life of 12 hours, should be held for 14 days prior to injection.

Prasugrel, with a half-life of about 7 hours, should be held for $7-10$ days prior to injection.

Ticagrelor, with a half-life of 7 hours, should be held for 5 days prior to injection.

The P2Y12 receptor blockers may be restarted 6 hours after injection (33-36).

GP Ilb/llla inhibitors such as Tirofiban, half-life of 2 hours, and Eptifibatide, half-life of 2.5 hours, should be held $4-8$ hours prior to procedure $(37,38)$.

Abciximab has a half-life up to 30 minutes however its platelet function effect can last up to 48 hours, so the drug should be held $24-48$ hours prior to injection (39).

The GP IIb/llla inhibitors may be re-dosed 2 hours after injection.

Aspirin should be discontinued for about one week prior to PRP therapy as it irreversibly inhibits platelet cyclooxygenase. The platelet effects can be seen for the duration of the platelet life span, 8 - 9 days.

Comparatively, non-steroidal anti-inflammatory drugs (NSAIDs) reversibly inhibit platelet cyclooxygenase. Typically utilized in short-acting form, these NSAIDs should be held the day prior to the procedure; depending on the half-life of the specific agent (40).

\section{Discussion}

PRP therapy has been well-documented across many sub-specialties in medicine. Its applicability to promote healing and regeneration continues to drive its expansion in subacute and chronic conditions. In the expanding cohort of patients, many PRP therapy candidates will also be on antithrombotic therapy. While there is limited literature on the timing of PRP injections during antithrombotic therapy, understanding the pharmacokinetics and platelet effects can help guide discussion on the proper timing of discontinuation and resumption of a particular antithrombotic agent (41).

The efficacy of PRP has partly been attributed to multiple growth factors and bioactive proteins in platelets that stimulate wound and soft tissue healing $(13,17)$. It is through the proliferation of differentiated cells, enhancement of collagen synthesis along with early angiogenesis and revascularization that PRP continues to show benefits of regeneration. These benefits are maintained in intact platelet cells. Platelet activation starts first with adhesion mediated through purinergic receptors on the platelet surface. Then, through a cascade system with mitochondrial hyperpolariza- 
Table 2. Summary of Recommendations.

\begin{tabular}{|c|c|c|c|c|c|}
\hline $\begin{array}{l}\text { Antithrombotic } \\
\text { Agent }\end{array}$ & Effect & Half-life & $\begin{array}{l}\text { Discontimue } \\
\text { prior to } \\
\text { procedure }\end{array}$ & $\begin{array}{c}\text { Resumption } \\
\text { after } \\
\text { procedure }\end{array}$ & Notes \\
\hline Warfarin & $\begin{array}{c}\text { Factors II, VII, IX, X } \\
\text { Inhibitor }\end{array}$ & $\begin{array}{l}20-60 \\
\text { hours }\end{array}$ & 4-5 days & 2 hours & \\
\hline Heparin & $\begin{array}{l}\text { Indirect Thrombin, } \\
\text { Factor } X_{\text {a Inhibitor }}\end{array}$ & 1.5 hours & $2-4$ hours & 1 hour & \\
\hline LMWH & $\begin{array}{l}\text { Indirect Thrombin, } \\
\text { Factor Xa Inhibitor }\end{array}$ & 4.5 hours & $\begin{array}{l}\text { Prophylaxis: } \\
\text { 10-12 hours } \\
\text { Therapeutic: } \\
24 \text { hours }\end{array}$ & $\begin{array}{l}\text { Prophylaxis: } \\
6-8 \text { hours } \\
\text { Therapeutic: } \\
24 \text { hours }\end{array}$ & \\
\hline Fundaparinux & $\begin{array}{c}\text { Synthetic Factor Xa } \\
\text { Inhibitor }\end{array}$ & $\begin{array}{l}17-21 \\
\text { hours }\end{array}$ & $36-42$ hours & $6-8$ hours & \\
\hline Rivaroxaban & Factor Xa Inhibitor & $5-9$ hours & $22-26$ hours & $4-5$ hours & \\
\hline Apixaban & Factor Xa Inhibitor & $\begin{array}{l}9-14 \\
\text { hours }\end{array}$ & $26-30$ hours & $4-6$ hours & \\
\hline Dabigatran & $\begin{array}{l}\text { Direct Thrombin } \\
\text { Inhibitor }\end{array}$ & $\begin{array}{l}12-17 \\
\text { hours }\end{array}$ & 7 days & 5 days & \\
\hline Clopidogrel & P2Y12 Receptor Blodker & $7-8$ hours & 7 days & 6 hours & \\
\hline Ticlodipine & P2Y12 Receptor Blocker & 12 hours & 14 days & 6 hours & \\
\hline Prasugrel & P2Y12 Receptor Blodker & 7 hours & $7-10$ days & 6 hours & \\
\hline Ticagrelor & P2V12 Receptor Blodker & 7 hours & 5 days & 6 hours & \\
\hline Tirofiban & GP IIb/IIIa inhibitor & 2 hours & 4-8 hours & 2 hours & \\
\hline Eptifibatide & GP Ib/IIla inhibitor & 2.5 hours & $4-8$ hours & 2 hours & \\
\hline Abciximab & GP IIb/Alla Inhibitor & $\begin{array}{c}30 \\
\text { minutes }\end{array}$ & 48 hours & 2 hours & $\begin{array}{l}\text { "platelet effect can } \\
\text { last up to } 48 \text { hour }\end{array}$ \\
\hline Aspirin & $\begin{array}{l}\text { Irrever sibly cox } \\
\text { Inhibitor }\end{array}$ & $\begin{array}{l}2-30 \\
\text { hours }\end{array}$ & $8-9$ days & 2 hours & $\begin{array}{l}\text { "platelet life span is } \\
8-9 \text { days. Half-life is } \\
\text { dose dependent }\end{array}$ \\
\hline NSAIDS & Reversible coX Inhibitor & $\begin{array}{l}2 \rightarrow 10 \\
\text { hours }\end{array}$ & 24 hours & 2 hours & $\begin{array}{c}\text { "half-life is dose and } \\
\text { agent dependent }\end{array}$ \\
\hline
\end{tabular}

tion, the platelet morphology undergoes changes. It is then that exocytosis of granules containing growth factors and proteins can be released allowing for PRP therapy's healing effects (21). Medications, particularly antithrombotic agents that modulate or affect the platelet surface membrane integrity can decrease the efficacy of PRP injections. Therefore there is a need to address an appropriate interval in which to discontinue and resume the antithrombotic agent. Once there is more research available it may be possible to categorize medications into high and low risk groups for their potential impairment of PRP based on their mechanism of action.

Taking into account the pharmacokinetics of the particular antithrombotic agent, the half-life can help guide the interval between discontinuation and resumption of the agent as it generally takes about 5 half-lives in order to be cleared from the system (Table 2). Medications such as aspirin exert an irreversible effect of platelets and will require termination prior to injection therapy of $8-9$ days, the life-span of platelets. Some study protocols held NSAIDs for up to 2 weeks after the procedure while other studies prohibited the use of NSAIDs for 48 hours post procedure $(42,43)$. The lack of uniformity often leads to NSAIDs being held for an undefined period of time in a study protocol with no clear answer on possible resumption (44-46). It has been reported in a single case report, a patient on chronic anti-platelet therapy that could not be held, had excellent results from a series of 3 PRP intra-articular knee injections (47). Regardless, the decision to hold or not hold antithrombotic medications needs to be seriously discussed with the risks and benefits thoroughly examined. So while the literature on the timing of PRP injec- 
tion in patients on antithrombotic agents is lacking, it is evident that the efficacy of PRP therapy is dependent on the intact surface membrane.

While there are no other studies looking at the timing of PRP injections during antithrombotic therapy, we offer a backbone on which to base future studies. There is a clear need to examine the efficacy relationship between particular antithrombotic agents and clinical outcomes after PRP. Additionally, studies comparing various intervals are needed to more finely elucidate the adequate timing from discontinuation of the agent to administration of the PRP. With the field of regenerative medicine continuously expanding, the implications for clinicians on this issue will continue to expand.

\section{Conclusion}

There is clearly a paucity of literature in regards to the safety, efficacy, and timing of PRP injections in patients with concomitant antithrombotic therapy. The importance of an intact platelet surface membrane allows for the appropriate release of the healing bioproteins and growth factors granting PRP therapy its efficacy. Antithrombotic agents that affect the stability of platelets will have an effect on PRP efficacy and must be discontinued at an appropriate time frame prior to injection therapy. With future research, the establishment of clinical practice guidelines concerning PRP and antithrombotic therapy can help structure safe and efficacious means in which to promote healing and regeneration in a growing patient population.

\section{References}

1. Ferrari M, Zia S, Valbonesi M, Henriquet $F$, Venere G, Spagnolo S, Grasso MA, Panzani I. A new technique for hemodilution, preparation of autologous platelet-rich plasma and intraoperative blood salvage in cardiac surgery. Int J Artif Organs 1987; 10:47-50.

2. Cole BJ, Seroyer ST, Filardo G, Bajaj S, Fortier LA. Platelet-rich plasma: Where we are now and where are we going? Sport Health 2010; 2:203-210.

3. International Cellular Medicine Society. 2012 Revision of the Best Practices Standards in Cell Based Medicine: Platelet Rich Plasma (PRP) Guidelines. www.cellmedicinesociety.org.

4. Vannini F, Di Matteo B, Filardo G, Kon E, Marcacci M, Giannini S. Platelet-rich plasma for foot and ankle pathologies: A systematic review. Foot and Ankle Surgery 2014; 20:2-9.

5. Hamid MS, Yusof A, Mohamed AM. Platelet-rich plasma (PRP) for acute muscle injury: A systematic review. PLoS ONE 2014; 9:e90538.

6. Andia I, Maffulli N. Platelet-rich plasma for muscle injury and tendinopathy. Sports Med Arthrosc 2013; 21:191-198.

7. Lei H, Gui L, Xiao R. The effect of anticoagulants on the quality and biological efficacy of platelet-rich plasma. Clin Biochem 2009; 42:1452-1460.

8. di Matteo B, Filardo G, Lo Presti M, Kon E, Marcacci M. Chronic anti-platelet therapy: A contraindication for platelet-rich plasma intra-articular injections? European Review for Medical ax
Pharmacological Sciences 2014; 18:55-59.

9. Dohan Ehrenfest DM, Andia I, Zumstein MA, Zhang CQ, Pinto NR, Bielecki T. Classification of platelet concentrates (Platelet-Rich Plasma-PRP, Platelet-Rich Fibrin-PRF) for topical and infiltrative use in orthopedic and sports medicine: Current consensus, clinical implications and perspectives. Muscles, Ligaments and Tendons Journal 2014; 4:3-9.

10. Nurden AT. Platelets, inflammation and tissue regeneration. Thromb Haemost 2011; 105:S13-S33.

11. Werner S, Grose R. Regulation of wound healing by growth factors and cytokines. Physiological Reviews 2003; 83:835-870.

12. Pietrzak WX, Eppley BL. Platelet rich plasma: biology and new technology. J Craniofac Surg 2005; 16:1043-1054.

13. Mehta V. Platelet-rich plasma: A review of the science and possible clinical applications. Orthopedics 2010; 33:111.

14. Mejia HA, BradleyJP. The effects of platelet-rich plasma on muscle. Basic Science and Clinical Application 2011; 19:149-153.

15. Wroblewski AP, Mejia HA, Wright VJ. Application of platelet-rich plasma to enhance tissue repair. Operative Techniques in Orthopaedics 2010; 20:98-105.

16. Marx RE. Platelet-rich plasma (PRP): What is PRP and what is not PRP? Implant Dent 2001; 10:225-228.

17. Kakudo N, Minakata T, Mitsui T, Kushida S, Notodihardjo FZ, Kusumoto K. Proliferation-promoting effect of platelet-rich plasma on human adipose- derived stem cells and human dermal fibroblasts. Plast Reconstr Surg 2008; 122:1352-1360.

18. Luengo Gimeno F, Gatto S, Ferro J, Croxatto JO, Gallo JE. Preparation of platelet-rich plasma as a tissue adhesive for experimental transplantation in rabbits. Thromb J 2006; 28:18.

19. Anitua E, Andia I, Ardanza B, Nurden P, Nurden AT. Autologous platelets as a source of proteins for healing and tissue regeneration. Thrombosis and Haemostasis 2004; 914-915.

20. Foster TE, Puskas BL, Mandelbaum BR, Gerhardt MB, Rodeo SA. Platelet-rich plasma: From basic science to clinical applications. Am J Sports Med 2009; 37:2259-2272.

21. Eppley BL, Woodell JE, Higgins J. Platelet quantification and growth factor analysis from platelet-rich plasma: Implications for wound healing. Plastic and Reconstructive Surgery 2004; 114:1502-1508.

22. Sánchez-González DJ, Méndez-Bolaina E, Trejo-Bahena NI. Platelet-rich plasma peptides: Key for regeneration. International Journal of Peptides 2012; e532519.

23. Iwase H, Ezzelarab MB, Ekser B, Cooper DK. The role of platelets in coagulation dysfunction in xenotransplantation and therapeutic options. Xenotransplantation 2014; 21:201-220.

24. Palta S, Saroa R, Palta A. Overview of the coagulation system. Indian ] Anaesth 2014; 58:515-523.

25. Oikonomopoulou K, Ricklin D, Ward P, 
Lambris JD. Interactions between coagulation and complement-their role in inflammation. Seminars in Immunopathology 2012; 34:151-165.

26. Holford NH. Clinical pharmacokinetics and pharmacodynamics of warfarin. Understanding the dose-effect relationship. Clin Pharmacokinet 1986; 11:483-504.

27. Estes JW. Clinical pharmacokinetics of heparin. Clin Pharmacokinet 1980; 5:204-220.

28. Boneu B, Caranobe C, Sie P. Pharmacokinetics of heparin and low molecular weight heparin. Baillieres Clin Haematol 1990; 3:532-544.

29. Donat F, Duret JP, Santoni A. The pharmacokinetics of fondaparinux sodium in healthy volunteers. Clin Pharmacokinet 2002; 41:1-9.

30. Mueck W. Stampfuss J, Kubitza D. Clinical pharmacokinetic and pharmacodynamic profile of rivaroxaban. Clin Pharmacokinet 2014; 53:1-16.

31. Frost C, Nepal S, Wang J, Schuster A, Byon W, Boyd RA, Yu Z, Shenker A, Barrett YC, Mosqueda-Garcia R, Lacreta F. Safety, pharmacokinetics and pharmacodynamics of multiple oral doses of apixaban, a factor $\mathrm{Xa}$ inhibitor, in healthy subjects. $\mathrm{Br} \mathrm{J}$ Clin Pharmacol 2013; 76:776-786.

32. Stangier J. Clinical pharmacokinetics and pharmacodynamics of the oral direct thrombin inhibitor dabigatran etexilate. Clin Pharmacokinet 2008; 57:285-295.

33. Karaźniewicz-Łada M, Danielak D, Burchardt P, Kruszyna L, Komosa A, Lesiak M, Glowka F. Clinical pharmacokinetics of clopidogrel and its metabolites in patients with cardiovascular diseases. Clin Pharmacokinet 2014; 53:155-164.

34. Desager JP. Clinical pharmacokinetics of ticlodipine. Clin Pharmacokinet 1994; 26:347-355.

35. Dobesh PP. Pharmacokinetics and pharmacodynamics of prasugrel, a thienopyridine $\mathrm{P}_{2} \mathrm{Y}_{12}$ inhibitor. Pharmacotherapy 2009; 29:1089-1102.

36. Butler K, Teng R. Pharmacokinetics, pharmacodynamics, safety and tolerability of multiple ascending doses of ticagrelor in healthy volunteers. $\mathrm{Br}$ ] Clin Pharmacol 2010; 70:65-77.

37. Kondo K, Umemura K. Clinical pharmacokinetics of tirofiban, a nonpeptide glycoprotein Ilb/Illa receptor antagonist: Comparison with the monoclonal antibody abciximab. Clin Pharmacokinet 2002; 41:187-195.

38. Gretler DD, Guerciolini R, Williams PJ. Pharmacokinetic and pharmacodynamic properties of eptifibatide in subjects with normal or impaired renal function. Clin Ther 2004; 26:390-398.

39. Harder S, Kirchmaier CM, Krzywanek HJ. Pharmacokinetics and pharmacodynamic effects of a new antibody glycoprotein IIb/IIla inhibitor (YM337) in healthy subjects. Circulation 1999; 100:1175-1181.

40. Needs CJ, Brooks PM. Clinical pharmacokinetics of salicylates. Clin Pharmacokinet 1985; 10:164-177.

41. Cavallari LH, Shin J, Perera MA. Role of pharmacogenomics in the management of traditional and novel oral anticoagulants. Pharmacotherapy 2011; 31:1192-1207.
42. Creaney L, Wallace A, Curtis M, Connell D. Growth factor-based therapies provide additional benefit beyond physical therapy in resistant elbow tendinopathy: A prospective, double-blind, randomised trial of autologous blood injections versus platelet-rich plasma injections. Br J Sports Med 2011; 45:966-971.

43. Finnoff JT, Fowler SP, Lai JK, Santrach PJ, Willis EA, Sayeed YA, Smith J. Treatment of chronic tendinopathy with ultrasound-guided needle tenotomy and platelet-rich plasma injection. PMR 2011; 3:900-911.

44. Gosens T, Peerbooms JC, van Laar W, den Oudsten BL. Ongoing positive effect of platelet-rich plasma versus corticosteroid injection in lateral epicondylitis: A double-blind randomized controlled trial with 2-year follow-up. Am J Sports Med 2011; 39:1200-1208.

45. Mishra A, Pavelko T. Treatment of chronic elbow tendinosis with buffered platelet-rich plasma. Am J Sports Med 2006; 34:1774-1778.

46. Peerbooms JC, Sluimer J, Bruijn DJ, Gosens T. Positive effect of an autologous platelet concentrate in lateral epicondylitis in a double-blind randomized controlled trial: Platelet-rich plasma versus corticosteroid injection with a 1-year follow-up. Am J Sports Med 2010; 38:255-262.

47. Matteo BD, Filardo G, Lo Presto M, Kon E, Marcacci M. Chronic anti-platelet therapy: A contraindication for platelet-rich plasma intra-articular injections? Eur Rev Med Pharmacol Sci 2014; 18:55-59. 
